\title{
CRITICALLY ANXIOUS
}

\author{
LAUREN GUILMETTE \\ Elon University
}

Sites of anxiety abound in 2020. For those of us who are already diagnosed and medicated as "anxious" - who would have no trouble finding plenty to worry about without the U.S. federal mishandling of a pandemic, without senseless state violence against unarmed people of color, and without the health risks of the coming semester of in-person classes - this year has brought new challenges. Anxiety is static noise, the absence of a radio signal but far from quiet. Anxiety can circulate as free-floating tension, dis-ease, eager to take hold. Writing demands sitting with the at-once buzzing and empty page, without judgment, to make something from the noise.

Reading, conversely, has offered me the respite of a coherent somewhere-else. This is not to suggest reading as a panacea for anxiety, and certainly not to universalize my experience into a picture of anxiety-as-such, but I do want to attend to the idea that reading can soothe. Reading - and here I include audio books and other modes of listening - offers a shift in the experience of time and space that is not simply escapist but more affirmatively relational, thinking-and-feeling-with, connecting to others across space, time, and generations. In a 1963 interview, James Baldwin famously said that he thought his own heartbreak to be "unprecedented in the history of the world" until he began to read. It was in reading that Baldwin learned "the things that tormented [him] most were the very things that connected [him] with all the people who were alive, or who had ever been alive" (89). I do not take this respite of the time to read lightly. It is a privilege of an unexpectedly open schedule, with the shift to remote teaching in Spring 2020, and some well-timed university press spring sales. It is also a gift - a rare talent and an offering - of authors who have honed concepts for naming experiences in their lived complexity.

Cressida J. Heyes's new book, Anaesthetics of Existence (2020), was of course written before the pandemic, but it may surprise us in its pandemic timeliness. The regularized workaday habits it describes - what Heyes calls "postdisciplinary time" - have been suddenly interrupted, broken, and so we may be able to discern them as we could not before. She observes that this post-disciplinary way of life presents a kind of neurological 
overload: the separation between work and life blurs into an at-once "ruthlessly linear and ... repetitious" checklist of tasks, oriented to the future with a generalized anxiety (Heyes 2020, 21). In response, post-disciplinary subject increasingly habituate themselves to seek out "anaesthetic time," respite from all tasks that can at times only be accomplished with the assistance of various drugs (105). Legally and socially approved forms of these drugs, like wine, are marketed to privileged (white, cis, straight, middle-class) women, Heyes writes, "as a respectable and politically unthreatening exit from the demands of the double shift," while they are stigmatized "as a dangerous and irresponsible practice for scapegoated groups." Importantly, Heyes does not criticize anaesthetic time but interprets it as "a logical response ... and a way of surviving in an economy of temporality that is relentlessly depleting" (99). Now, alongside the piling wreckage of current events, we navigate the breakdown of synchronized post-disciplinary activity - shared schedules, spaces, conferences for which papers were due - and likewise have an opportunity to examine our habits of seeking anaesthetic time.

Under pre-pandemic circumstances, my anxiety made me a well-behaved subject of post-disciplinary power, as I suspect it does for many of us in academia who multi-task and rush from meeting to meeting, propelled by we-know-not-what. Now, my anxiety spikes and spirals without recourse to the usual coping mechanisms, however flawed these cycles of caffeination and anesthesia may have been. Free-floating anxiety is capable of attaching to any number of contents without the sense-making infrastructure of everyday busy-ness. As familiar grooves of habit are disrupted, the contents to which anxiety might attach proliferate.

Sometimes it stops me short, reduces the trajectory of theoretical arguments midsentence to murmuring mush. At other times, it offers an uncanny revelation of sorts, offering a perspectival shift by which once-unthinking habits appear as strange. While it exceeds the scope of this short musing, I think this latter trajectory and its fleeting uncanniness can be better understood in light of Lynne Huffer's poetic insights on "erotic time": a spiraling temporal experience that "estranges us" from Western notions of historical progress, "from the certainty of time as our time, as a time that ends in us" (2020, 98). How might we not only navigate and tolerate but even honor the realizations brought to us by the collapse of post-disciplinary time, without then reductively formulating them as concepts for the very hyper-utilization they are intended to resist?

Heyes's method shares commonalities with what Lisa Guenther and others have called "critical phenomenology," which draws on phenomenological engagement with lived experience and genealogical engagement with its historical conditions (Guenther 2020, 19; Salamon 2018). "Critical" here designates an emphasis on the contingent (nonnecessary) formation of institutions, practices, and other conditions of lived experience. Critical phenomenology thus enables analysis of systemic forms of oppression as "quasitranscendental" structures of consciousness, "ways of making the world that go unnoticed without a sustained practice of critical reflection" (Guenther 2020, 12). While post- 
disciplinary time and its "after hours" repercussions are not accessible to "classical" transcendental phenomenology, critical phenomenology can bring them into focus for us, making it an adept method for engaging with present-day anxiety.

This spring, I came across the earliest mention I've yet found of "critical phenomenology," in Kathleen Woodward's Statistical Panic (2009). Woodward invokes the method to situate emotions in relation to power and socio-historical context (10-11). Emotions and other felt experiences have been all too often privatized and depoliticized. Against this, Woodward observes that feminists have long discerned anger as a site of embodied judgment, one that registers and responds to "unequal relations of power" (47). We might extend Woodward's point to recent expressions of grief, anger, and anxiety (but also solidarity) in U.S. protests against police brutality and in support of Black lives. In light of extra-legal police murders, it is all the more fraught to maintain that anxiety should be overcome. How might these negative affects be directed toward the transformation of the unjust conditions that produce them? Thus, Audre Lorde wrote that anger can act as a spotlight toward growth, motivating a different arrangement $(1984,124)$. Critical phenomenology, because it contains the genealogical understanding that our lived conditions are non-necessary, can resist the depoliticization of affect, taking these felt responses seriously as challenges to the present order.

Returning to my earlier question: how, instead of being overcome, might anxiety and other felt tensions be honored and even honed as interpretive responses to present conditions? Gloria Anzaldúa develops the term la facultad to name an increased sensitivity, a warning system to protect from threats, cultivated and more highly sensitized in those who have faced intersecting forms of oppression $(1987,60)$. So, I wonder whether a critical phenomenology of anxiety, felt initially as static background noise, can draw upon Anzaldúa's la facultad to cultivate a "critical anxiety" - or, what we might call a sensory-affective capacity - for a post-disciplinary world. And, if the current situation in fact indicates the partial or total collapse of post-disciplinary time, how might a critically sharpened sense of our release from this time prepare our sensory-affective capacities productively, to envision a less ruthlessly ordered future?

Acknowledgment: Thanks to Robert Leib, Rebecca Longtin, Libby Coyner, Shepherd Tsosie, Randall Johnson, Foel Michael Reynolds, and the co-editors of this issue for insights and comments.

\section{REFERENCES}

Anzaldúa, Gloria. 1987. Borderlands/La Frontera. San Francisco: Aunt Lute Books.

Baldwin, James, interviewed by Jane Howard. 1963. "Doom and Glory of Knowing Who You Are.” LIFE Magazine 54 (21): 89. 
Guenther, Lisa. 2020. "Critical Phenomenology.” 50 Concepts for a Critical Phenomenology, edited by Gail Weiss, Ann V. Murphy, and Gayle Salamon, 11-16. Evanston, IL: Northwestern University Press.

Heyes, Cressida J. 2020. Anaesthetics of Existence: Essays on Experience at the Edge. Durham, NC: Duke University Press.

Huffer, Lynne. 2020. Foucault's Strange Eros. New York: Columbia University Press.

Lorde, Audre. 1984. Sister Outsider. New York: Crossing Press.

Salamon, Gayle. 2018. "What's Critical about Critical Phenomenology?" Puncta: Journal of Critical Phenomenology 1: 8-17.

Woodward, Kathleen. 2009. Statistical Panic: The Cultural Politics and Poetics of Emotion. Durham, NC: Duke University Press. 